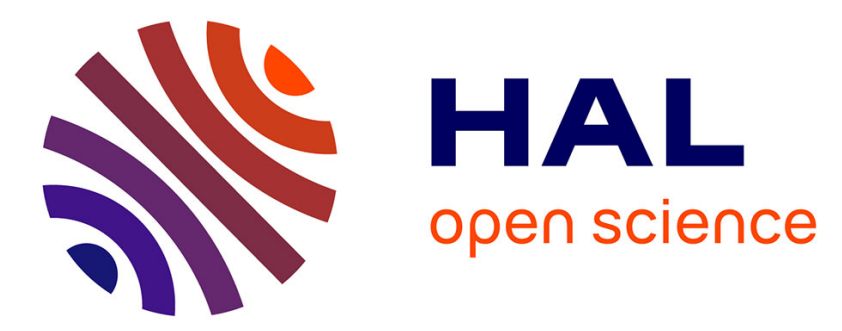

\title{
Factors influencing the recurrence of arterial involvement after surgical repair in Behçet disease
}

Julien Gaudric, Jérémie Jayet, David Saadoun, Thibault Couture, Yasmina

Ferfar, Jean Michel Davaine, Patrice Cacoub, Laurent Chiche, Fabien Koskas

\section{- To cite this version:}

Julien Gaudric, Jérémie Jayet, David Saadoun, Thibault Couture, Yasmina Ferfar, et al.. Factors influencing the recurrence of arterial involvement after surgical repair in Behçet disease. Journal of Vascular Surgery, 2020, 72 (5), pp.1761-1769. 10.1016/j.jvs.2020.01.076 . hal-03060532

\section{HAL Id: hal-03060532 \\ https://hal.sorbonne-universite.fr/hal-03060532}

Submitted on 14 Dec 2020

HAL is a multi-disciplinary open access archive for the deposit and dissemination of scientific research documents, whether they are published or not. The documents may come from teaching and research institutions in France or abroad, or from public or private research centers.
L'archive ouverte pluridisciplinaire HAL, est destinée au dépôt et à la diffusion de documents scientifiques de niveau recherche, publiés ou non, émanant des établissements d'enseignement et de recherche français ou étrangers, des laboratoires publics ou privés. 


\section{Factors influencing the recurrence of arterial involvement after}

\section{2 surgical repair in Behçet's disease}

3

4

5

6

7

8

9 From the aPHP, Pitié-Salpêtrière Hospital, Sorbonne Universités, Department of Vascular

Julien Gaudric $^{\mathrm{a}}$, Jérémie Jayet ${ }^{\mathrm{a}}$, David Saadoun ${ }^{\mathrm{b}}$, Thibault Couture ${ }^{\mathrm{a}}$, Yasmina Ferfar ${ }^{\mathrm{b}}$, Jean

Michel Davaine ${ }^{\mathrm{a}}$, Patrice Cacoub ${ }^{\mathrm{b}}$, Laurent Chiche ${ }^{\mathrm{a}}$, Fabien Koskas ${ }^{\mathrm{a}}$

Surgery, 47-83, bd de l'Hôpital, 75013 Paris, France and ${ }^{\text {b} A P H P, ~ P i t i e ́-S a l p e ̂ t r i e ̀ r e ~ H o s p i t a l, ~}$ Sorbonne Universités, Department of Internal Medicine, 47-83, bd de l'Hôpital, 75013 Paris, France.

Corresponding author: Julien Gaudric, MD, Department of Vascular Surgery, PitiéSalpêtrière Hospital, 47-83, bd de 1’Hôpital, 75013 Paris, France.

E-mail: julien.gaudric@aphp.fr

Phone Number: +33663739002

This study was presented in the plenary session at the 2019 Vascular Annual Meeting of the French Society for Vascular and Endovascular Surgery, Lille, June 28-30, 2019.

This study has been selected for fast-track presentation at the 2019 Vascular Annual Meeting of the European Society for Vascular and Endovascular Surgery, Hamburg, September 24-27, 
Type of Research: single center retrospective study

Key Findings: Twenty-three patients with BD, had aortic and peripheral arterial repair between May 1996 and September 2015. Twenty-four recurrences were noted and forty-seven surgical procedures were performed. Mean follow-up was $8.4 \pm 7.5$ years. Initial arterial lesions were aneurysms and thrombosis in $85 \%$ and $15 \%$ of cases, respectively. Recurrence rate was $51 \%$.

Preoperative medical treatments, including colchicine, steroids or immunosuppressants, significantly decreased recurrence rate: $28 \%(7 / 25)$ versus $75 \%(15 / 20)$ in untreated patients $(\mathrm{P}=0.002)$. When anastomoses were protected using a prosthetic sleeving technique, the recurrence rate was threefold lower $(\mathrm{P}=0.08)$.

Take home Message: Vascular Behçet's disease is responsible for a high rate of recurrence after surgical repair. Perioperative immunosuppressants are essential to reduce this risk. The additional surgical technique consisting in sleeving anastomosis may help to reduce pseudoaneurysm recurrences occurring at the same site in $92 \%$ of cases. 
49 Recurrence after surgical repair occurred in $51 \%$ of cases in this retrospective study of 23

50 patients with non-pulmonary arterial involvement of BD. Immunosuppressive treatment but 51 also mechanical sleeving of the anastomosis decrease recurrence rates.

52 
54 Introduction: Arterial involvement in Behçet's disease (BD) is rare and its surgical management is a major concern because of its high recurrence rate. This study evaluated the influence of the surgical technique, device, and immunosuppressive treatment used on the postoperative recurrence in patients with non-pulmonary arterial BD.

Methods: Single center retrospective study conducted in 23 patients meeting the International Study Group of BD criteria, who underwent surgery for arterial involvement between May 1996 and September 2015. Recurrence was defined as the occurrence of arterial aneurysm or thrombosis during follow-up. Perioperative medical treatment and surgical technique used were reported.

Results: Forty-seven surgical procedures were performed in 23 patients. Mean follow-up was $8.4 \pm 7.5$ years. Initial arterial lesions were aneurysms and thrombosis in $85 \%$ and $15 \%$ of cases, respectively. Arterial lesions were aortic and peripheral in $48 \%$ and $52 \%$ of cases. Recurrence rate was $51 \%$. Recurrences occurred within less than one year in $24 \%$ of cases and at the same anatomical site in $92 \%$ of cases. Among the 24 recurrences, 17 were false aneurysms, 6 were thrombosis and one was a true aneurysm in a different arterial site. To treat the arterial lesion, direct anastomosis was performed in 6 cases, bypass using the saphenous vein, graft or allograft was performed in 6, 27 and 5 cases, respectively, and stentgraft was used in 3 cases. Vascular lesions involved the aorta in 19 cases and a peripheral artery in 28 cases.

Preoperative medical treatments, including colchicine, steroids or immunosuppressants, 74 significantly decreased recurrence rate: $28 \%(7 / 25)$ versus $75 \%(15 / 20)$ in untreated patients $(\mathrm{P}=0.002)$. The recurrence rate was $42.5 \%(17 / 40)$ in patients treated postoperatively versus $80 \%(4 / 5)$ in untreated patients. The nature of the device used (vein, prosthetic graft, allograft, stent graft or direct anastomosis) did not change the risk of recurrence. When anastomoses 
78 were protected using the prosthetic sleeving technique, the recurrence rate was three times

79 lower $(\mathrm{P}=0.08)$.

80 Conclusion: Relapse is a main concern after surgical repair of arterial BD. This study

81 suggests the need for targeted perioperative medical management to reduce the risk of arterial

82 recurrence in BD patients. To this end, a multidisciplinary approach is mandatory.

83 The use of sleeve anastomosis is associated with a numerically lower risk of recurrence.

84 However, further studies are needed to confirm this efficacy.

85

86

87 Key words: Vascular Behçet's disease, aneurysm, recurrence, sleeve anastomosis.

88

89

90

91 Conflict of interest: None

92 

recurrence of arterial lesions in BD patients with non-pulmonary arterial involvement.

Behçet's disease (BD) is a chronic, relapsing, multisystemic disorder characterized by mucocutaneous, ocular, vascular and central nervous system manifestations ${ }^{1,2}$. The pathogenesis of the disease remains unknown, although a genetic predisposition, environmental factors, and immunological abnormalities have been reported ${ }^{3,4}$. Vasculitis is thought to underlie the clinical manifestations of $\mathrm{BD}$ and is distinguishable because both arteries and veins of all sizes are involved. Arterial complications are less common than venous lesions in BD, and occur in $1-14 \%$ of patients ${ }^{5-8}$. Vascular BD (VBD) patients are at risk of multiple vessel-related complications resulting in an increased risk of mortality. Indeed, the 20 -year survival rate decreases from 89 to $73 \%$ in case of arterial disease ${ }^{9}$. In a large cohort of $817 \mathrm{BD}$ patients, Saadoun et al. ${ }^{8}$ have shown an overall mortality rate of $5 \%$ after a median follow-up of 7.7 years. In this series, the incidence of arterial involvement was 3 times higher in patients who died. Unlike venous manifestations ${ }^{10-15}$, arterial involvement in $\mathrm{BD}$ is rare and a few publications have reported its specific treatment. Vascular surgery is challenging in $\mathrm{BD}$ patients and the mortality rate is $\operatorname{high}^{16}$, mainly due to anastomotic aneurysm relapses and graft thrombosis.

There is currently no consensual technique for the surgical management of these patients. The vascular substitutes that can be used include prosthetic materials, venous autografts, arterial allografts or stent grafts 9 . The main concern in these patients, apart from bypass thrombosis, is the formation of anastomotic pseudoaneurysms in the short term, requiring iterative interventions that may be life-threatening in case of rupture.

The aim of this study was to retrospectively identify the factors influencing the postoperative

\section{Patients and methods}


119 It was a single center retrospective study conducted in 23 BD patients meeting the 120 international criteria for $\mathrm{BD}^{17}$ who consulted the Departments of vascular surgery and internal 121 medicine of the Pitié-Salpêtrière Hospital, Paris, France between May 1996 and September 1222015.

123 Associated clinical signs were genital and oral ulcerations, uveitis, folliculitis, arthralgia, and 124 fever. Other aneurysmal locations, a history of deep vein thrombosis and cardiovascular risk 125 factors were identified. Pre- and post-operative medical treatments were recorded. Patients 126 with BD requiring arterial repair in our department were systematically included in the study 127 whether it was a recurrence or a primary surgery. In case of previous arterial repair in another 128 center, the first surgical repair in our department was considered a recurrence. Arterial lesions were defined by the presence of aortic or peripheral aneurysm, pseudoaneurysm or arterial

130 thrombosis. The presence of a potential triggering trauma was also investigated for each 131 arterial lesion. Patients who did not require surgery or with pulmonary artery aneurysms were 132 excluded from the analysis. The indications for surgery were: symptomatic arterial 133 thrombosis; aortic aneurysm greater than $5 \mathrm{~cm}$ in diameter or growing by more than $5 \mathrm{~mm}$ in 1346 months, or becoming symptomatic; pseudoaneurysm of more than $2 \mathrm{~cm}$ in diameter or 135 growing. Emergency management was limited to ruptured aneurysms or patients with acute 136 ischemia. The radiological diagnosis of aneurysm or pseudoaneurysm was based on arterial 137 Doppler ultrasound combined with computed tomography (CT)-scan. The surgical technique 138 and the material used (prosthetic graft, saphenous autograft, arterial allograft, or stent) were 139 analyzed according to the different anatomical locations. Bypass anastomosis was performed 140 as usual. The choice of the technique used was left to the referee surgeon's discretion. In some 141 cases, a sleeving protection was used, consisting in locating a short prosthetic graft segment 142 around the vascular anastomosis (figures 1 and 2) to reinforce it and to prevent secondary 
143 pseudoaneurysm formation. This technique was used when the diagnosis of VBD was

144 confirmed or strongly suspected. In these cases, a sleeve protection was used on each end-to-

145 end anastomosis remote from a bifurcation. For large bypasses (diameter $>8 \mathrm{~mm}$ ), the same

146 graft segment is used for sleeving. For $\leq 8 \mathrm{~mm}$ bypasses, a larger $(+1 \mathrm{~mm})$ segment than the

147 bypass graft is required to avoid stenosis.

148 The postoperative follow-up was based on clinical examination and ultrasound or CT-scan.

149 The primary patency rate was calculated.

150 A recurrence was defined as the reappearance of aneurysm or pseudoaneurysm at the operated

151 site or in another location, or by the occurrence of bypass thrombosis.

152 Early recurrence was defined as the occurrence of arterial aneurysm within less than 1 year,

153 confirmed by arterial Doppler ultrasound or CT-scan. Global doppler ultrasound was

154 systematically performed 6 months after surgery and yearly thereafter during the follow-up.

155 In case of thoracic aortic repair, a CT-scan was performed at the same timepoints. Recurrence

156 at the same arterial site and recurrence at a new site were differentiated. The follow-up was

157 performed by the surgical department and by the referent BD medical department located in

158 the same hospital.

159 The number of recurrences was compared according to the nature of the implanted arterial

160 substitute: synthetic graft, venous autograft, arterial allograft, or stent. The effect of sleeve

161 anastomosis on recurrences was assessed. The recurrence rate in patients receiving dedicated

162 medical treatment for $\mathrm{BD}$ was also compared to the recurrence rate in untreated patients,

163 including those who could have benefited from a sleeving or not. Steroids and

164 immunosuppressive treatment were systematically prescribed prior to surgery in BD patients

165 from our institution. However, in some cases, no immunosuppressive treatment was given

166 when patients where referred from other centers or when the diagnosis of BD had not been

167 confirmed prior to surgery. 
169 Ethical issues

170 The study was conducted in accordance with the ethical principles of the Declaration of 171 Helsinki.

172 The study protocol was assessed by the institutional review board of the Hôpital Universitaire

173 Pitié-Salpêtrière. Patients were informed that their clinical data were likely to be collected,

174 but in accordance with the French law, since this was an observational study involving only 175 routine clinical practices and therefore with no risk for patients, no informed consent was 176 needed.

$178 \quad$ Statistical analysis

179 Statistical analyses were carried out using SAS 9.4 software. Quantitative data with normal 180 distribution are expressed as the mean \pm standard deviation and quantitative data with non181 normal distribution as the median (interquartile). The recurrence rate according to the effect

182 of the anastomotic sleeve technique was assessed using the Kaplan-Meier method. The

183 Fischer's exact test was used to study the effect of preoperative and postoperative treatments

184 on the occurrence of recurrences (thrombosis, false aneurysm). A P-value less than 0.05 was 185 considered statistically significant.

\section{Results}

188 Population

189 Twenty-three BD patients with arterial involvement were included in our study. A total of 47

190 procedures were performed for arterial lesion, with a mean number of $2.4 \pm 0.6$ procedures

191 per patient in the 17 patients who experienced recurrence. Except for 7 initial interventions

192 performed in another hospital before the diagnosis of $\mathrm{BD}$, all interventions were performed in 
our department, including after relapses. Patient demographics are presented in Table I. At the

194 time of arterial lesions, the main active clinical sign of BD was oral and genital ulcerations in

$19561 \%$ of cases. Peripheral locations were more common than aortic ones (Table II).

196 Among patients with peripheral aneurysms, the femoro-popliteal location (48\%) was the most

197 common. Among all patients, the first arterial involvement was fusiform aneurysm $(\mathrm{n}=10)$,

198 pseudoaneurysm $(n=12)$, or arterial thrombosis $(n=1)$. During the follow-up, including

199 relapses, the treated lesions were pseudoaneurysms in 29 procedures (62\%), fusiform 200 aneurysms in 11 procedures $(23 \%)$ and arterial thrombosis in 7 procedures $(15 \%)$. The lesions 201 were bilateral in 2 patients (4\%): one patient had bilateral iliac thrombosis and one patient had 202 spontaneous bilateral femoral pseudoaneurysms. Arterial puncture resulted in 203 pseudoaneurysm in 2 cases (4\%). Emergency management for ruptured aortic 204 pseudoaneurysm below the renal arteries was needed in two cases (4\%).

206 Surgical technique

207 Among the 47 procedures, 27 prosthetic grafts (57\%), 6 venous autologous grafts (13\%), 5 208 cryopreserved allografts (11\%) and 3 stent grafts (6\%) were used (Table III). Prosthetic grafts 209 were polyethylene terephthalate (PET) in all cases except one. In this case, graft made with 210 polytetrafluoroethylene (PTFE) was used. All anastomoses were performed using 211 polypropylene suture thread. Stent grafts used were Valiant thoracic endograft (Medtronic, 212 Santa Rosa, CA, USA) in one case and covered stents in two cases (fig 3) for peripheral 213 aneurysms. In 6 cases, reconstruction did not require any material (13\%) because short 214 resection with direct end-to-end anastomosis could be performed. The vascular substitutes 215 used, depending on the lesion location, are shown in Table III. A total of 95 anastomoses 216 were performed during the 47 procedures. The sleeving technique was used for 25 217 anastomoses (corresponding to 13 bypass procedures): 23 (92\%) were graft-to-artery 
anastomosis (8 aortic, 3 iliac, 11 femoral, and 1 popliteal) and $2(8 \%)$ were venous-to-femoral

219 artery anastomosis.

220 The mean follow-up duration was $8.4 \pm 7.5$ years. The postoperative mortality rate was $2 \%$.

221 One patient died 1 month after surgery. This patient underwent aortic stent graft in zone 0

222 with supra-aortic trunk debranching for false aneurysm of the aortic arch. He experienced a

223 septic rupture of the brachiocephalic trunk anastomosis due to Staphylococcus aureus graft

224 infection. The postoperative morbidity rate was $8 \%$ (4/47). Two patients experienced

225 hematoma at the surgical site, one patient had acute renal failure without dialysis after aortic

226 surgery, and one patient had acute lower limb ischemia due to embolization after treatment of

227 abdominal aortic aneurysm.

228 The 5-year primary and secondary patency rates were 94 and 100\%, respectively.

229 All patients received antiplatelet therapy (160 mg of acetylsalicylic acid) after bypass surgery

230 regardless of the substitute used. In case of thrombosis, anticoagulant treatment (vitamin $\mathrm{K}$

231 antagonist) was initiated instead of antiplatelet therapy.

\section{Recurrence after vascular repair}

234 A total of 24 recurrences were observed in 17 patients, corresponding to a recurrence rate of $23551 \%$. Eleven patients $(48 \%)$ had 1 recurrence, 5 patients $(22 \%)$ had 2 recurrences and 1 236 patient (4\%) had 3 recurrences. In 22 cases (92\%), the same arterial anatomical site was 237 involved. Only two patients experienced a recurrence in a different site: one patient had 238 contralateral common femoral artery pseudoaneurysm and one had aortic dilation above a 239 previous infra-renal aortic repair.

240 Lesions recurred as anastomotic pseudoaneurysm in $71 \%$ of cases (17/24), bypass thrombosis 241 in $25 \%$ of cases $(6 / 24)$ and aortic fusiform aneurysm above previous infra-renal aortic 242 aneurysm repair in $4 \%$ of cases (1/24). Graft thrombosis occurred in three patients (femoro- 
243 femoral bypass in two cases and aorto-aortic graft in one case). Graft thrombosis recurred 244 one, two and three times respectively in these three patients.

245 The mean time to recurrence for the overall population was $65 \pm 68$ months. Among the 24 246 recurrences, 7 (24\%) occurred within one year. In the 16 cases that relapsed after one year, 247 the mean time to recurrence was $79.6 \pm 59$ months. In this group, the median time between 248 the first arterial repair and the first recurrence was 45 months (1-232) and it was 18 months 249 (6-143) between the second intervention and the second relapse. In one patient, the time 250 between the third intervention and the third relapse was 20 years. Recurrences according to 251 the time are presented in Figure 3.

252 Anastomotic pseudoaneurysm occurred within the first year in $41 \%$ of cases $(7 / 17)$.

253 The nature of the recurrence observed according to the type of arterial repair is shown in 254 Table IV. The differences highlighted were not statistically significant due to the small size of 255 the sample.

256 In 45 out of the 47 procedures performed, the use of pre- or postoperative immunosuppressive 257 treatment was known. Medical treatment included colchicine, steroids or 258 immunosuppressants. Patients received medical treatment preoperatively in $55 \%$ of cases 259 (25/45), postoperatively in $89 \%$ of cases (40/45) and both pre- and postoperatively in $51 \%$ of 260 cases (23/45). No medical treatment was given in $11 \%(5 / 45)$ of cases. Perioperative medical 261 treatments are detailed in Table V.

262 The effect of preoperative immunosuppressive treatment on the recurrence rate showed that $26328 \%$ of procedures $(7 / 25)$ were followed by a recurrence in treated patients compared to $75 \%$ $264(15 / 20)$ in untreated patients (OR: 7.31; 95\% CI $(1.73 ; 36.81))(\mathrm{P}=0.002)$.

265 The effect of postoperative immunosuppressive treatment was also assessed. Forty-two 266 percent of patients who received postoperative treatment (17/40) experienced a recurrence 267 versus $80 \%$ of untreated patients (4/5) (OR: 5.22; 95\% CI $(0.46 ; 277.32))(\mathrm{P}=0.16)$. 
All patients who did not receive any medication before or after surgery (5/5) experienced a recurrence.

270 The effect of the sleeving technique on the occurrence of pseudoaneurysms at anastomosis 271 sites was analyzed and each anastomosis was considered according to the use of a sleeve 272 protection or not. A total of 95 anastomoses were performed, of which 25 were sheathed by a 273 sleeve. The overall pseudoaneurysm rate was $18 \%$ (17/95 anastomoses). In the absence of 274 sleeve, the false aneurysm rate was $21 \%(16 / 70)$ but it was only $8 \%(2 / 25)$ in the presence of 275 a sleeve (OR: 2.44; 95\% CI $(0.89 ; 6.73))(\mathrm{p}=0.08)$ (Figure 4).

276 Regarding patients who received pre- and postoperative medical treatments without sleeve, 277 the recurrence rate for each anastomosis was 32\% (12/38 anastomoses), while patients who 278 received medical treatments and sleeve showed a recurrence rate of only $10 \%(2 / 19$ 279 anastomoses) (OR: 0.26; 95\% CI $(0.03 ; 1.4))(\mathrm{p}=0.108)$.

\section{Discussion}

283 We provide here the results of a large series of patients who underwent a vascular procedure 284 for arterial lesions of BD. The postoperative mortality rate was low but we observed a high 285 rate of relapse following surgical procedures comparable to those previously published, 286 although our follow-up of 8.4 years was longer ${ }^{18-24}$. In our series, $51 \%$ of BD patients 287 operated for arterial lesions (aneurysms or thrombosis) experienced a relapse which occurred 288 during the first year following surgery in one third of cases.

289 In previous series, recurrence rates of $50 \%$ and $56 \%$ and postoperative mortality rates of $14 \%$ 290 and $15 \%$ have respectively been reported in 32 patients who underwent bypass ${ }^{25-29}$ and in 48 291 patients who underwent graft interposition ${ }^{22,26,28-30}$.

\section{Device}


293 Vasculitis in BD is distinguishable because both arteries and veins of all sizes are involved.

294 Venous complications are more common than arterial lesions in BD, occurring in $30 \%$ of 295 patients ${ }^{5-7}$. VBD patients are at risk of multiple vessel-related complications ${ }^{9,27,31}$. Because 296 of the risk of concomitant venous failure due to BD, we did not use the saphenous vein except 297 in specific cases such as distal bypass or septic surgery. In this study, we used saphenous 298 vein grafts in only $13 \%$ of cases and the complication rate was of $50 \%$, exclusively due to 299 pseudoaneurysm formation. In fact, results did not significantly differ from those of prosthetic 300 grafts, but these findings should be interpreted with caution because of the small number of 301 venous bypass procedures performed.

302 The use of prosthetic grafts was associated with a relapse rate of $43 \%$. Thrombosis and 303 pseudoaneurysm occurred after 4/27 (14.8\%) and 9/27 (33.3\%) procedures, respectively.

304 Thrombosis could be explained by the hypercoagulability secondary to inflammation due to 305 BD in these young patients without atheroma ${ }^{32}$.

306 Arterial allograft could be another option as we observed a lower complication rate of $20 \%$, 307 but in a limited number of cases (1/5 cases).

308 Arterial wall injury secondary to anastomosis performed between a native artery and a vein or 309 prosthetic graft is a local risk factor for relapse. The endovascular approach has recently been 310 shown to improve results ${ }^{18}$ although there may be trauma between a stent and the vascular 311 wall. The endovascular approach was used in only $6 \%$ of cases in our study and did not allow 312 concluding to any difference. The endovascular approach could be effective because no 313 anastomosis is needed. The stent should be long enough to cover the lesion in order to seal in 314 a healthy part of the vessel ${ }^{33}$. However, arterial puncture is a risk factor for pseudoaneurysm 315 formation $^{23,34,35}$ ( 3 cases in our study). Moreover, data on the long-term results are limited in 316 the literature ${ }^{36}$. 
317 Endovascular procedures are also increasingly used in the management of $\mathrm{BD}$, but their

318 superiority has not been demonstrated. Except for Balcioglu et $\mathrm{al}^{37}$ who have not observed 319 any aneurysm formation nor thrombosis after aortic stent graft placement after a median 320 follow-up of 40 months, all other series have reported a recurrence rate ranging between 8.3 321 and $75 \%$ after endovascular procedures ${ }^{18-21,29,34,38-40}$. Many cases of pseudoaneurysms at the 322 proximal or distal margin of the stent graft have been described $21,35,40,41$ and resulted in 323 patient death in three cases due to rupture ${ }^{19,29,40}$. Despite the less invasive nature of 324 endovascular treatment, interactions between the stentgraft and the vascular wall led to the 325 formation of pseudoaneurysms at both ends. Yin et $\mathrm{al}^{18}$ have shown that limiting the 326 oversizing to less than $5 \%$ could decrease this risk.

327 Liu et $\mathrm{al}^{20}$ have shown better results with bypass surgery than with stent graft in 18 328 procedures on peripheral arteries. However, the results of aortic aneurysm exclusion were 329 disappointing: among 22 procedures for aortic pseudoaneurysms, a stent graft was used in 19 330 cases, resulting in recurrence and mortality rates of $18 \%$ and $16 \%$, respectively, after a short 331 median follow-up of 23 months. Kim et $\mathrm{al}^{23}$ have reported the experience of 20 aneurysms in 33216 patients treated with stent grafts after a mean follow-up of 4 years. The relapse rate of $19 \%$ 333 was low compared to 8 aneurysms in 7 patients who underwent open repair with a relapse rate 334 of $43 \%$.

335 However, the technique consisting in performing bypass without anastomosis, as described in 336 the Viabahn Padova sutureless technique, could be an option ${ }^{42}$.

\section{Relapses}

339 In the present study, the recurrence involved the same arterial anatomical site in $92 \%$ of cases.

340 Patients who received perioperative steroids and/or immunosuppressants showed a reduced 341 risk of relapse. In line with previous studies and the European League Against Rheumatism 
342 (EULAR) recommendations ${ }^{20,26,27,31,36,37,43}$, anastomotic relapses and graft thrombosis in

343 this series were less common in patients who received aggressive perioperative medical 344 treatment (corticosteroids and immunosuppressants).

345 In our series, patients were treated preoperatively in only $45 \%$ of cases but in these cases, the 346 recurrence rate was significantly reduced compared to that found in untreated patients (28\% 347 versus $75 \%$ ). In most cases, BD was not diagnosed at the time of surgery.

348 The use of postoperative treatments effectively decreased the recurrence rate of arterial 349 lesions.

350 Many recurrences (24\%) occurred during the first year following the surgical procedure but 351 most of them (76\%) were delayed with a mean time to recurrence of 6.5 years. These results 352 showed that the risk of recurrence was sustained, whereas in the literature the mean time to 353 recurrence is 10.5 months after a mean follow-up of 6 years ${ }^{24,31,32,39}$. However, there is 354 currently no consensus regarding the postoperative follow-up of these patients. Therefore, 355 extended monitoring with repeated Doppler ultrasound explorations could be useful to detect 356 as soon as possible early and delayed local recurrences or monitoring with CT-scan for 357 thoracic aorta and intrathoracic supra-aortic trunks.

$\underline{\text { Sleeve anastomosis }}$

360 We showed that recurrences occurred mainly at the same site, especially anastomotic 361 pseudoaneurysms, even when optimal medical treatment was given. That is why we added a 362 surgical technique to decrease this risk. Sleeve protection of the anastomosis is an easy and 363 reproducible technique consisting in reinforcing arterial anastomosis by wrapping it with a 364 larger prosthetic graft. This technique had previously been described ${ }^{34,44}$ but its effects on the 365 risk of recurrence had never been specifically investigated. In our series, we found that 366 anastomoses protected by a sleeve were less often affected by false aneurysm during the 
follow-up than those that were not protected. This extra-arterial reinforcement provides a

368 mechanical support that decreases the risk of secondary anastomotic rupture, although this

369 result was not statistically significant and further studies are needed to confirm it.

370 This technique was not systematically used when the diagnosis of BD was not suspected at 371 the time of the first surgical procedure or when anastomosis was too close to a collateral 372 artery (such as renal artery or profoundis femoral artery). After a mean follow-up of 8 years, it 373 appeared that the rate of anastomotic false aneurysms was decreased when a sleeve was used. 374 Furthermore, even in patients who received medical treatment, adding a sleeve also decreased 375 the risk of anastomotic false aneurysm. The recurrence rate dropped from $32 \%$ to $10 \%$ of all 376 anastomoses when a sleeve was associated with the surgical procedure.

378 The main limitation of this study is its retrospective design. This disease is not common and 379 the diagnosis is often made after the occurrence of one or two arterial events, which limits the 380 possibility of a prospective approach. Moreover, given the small number of patients, the risk 381 of a type 2 statistical error cannot be ruled out. For this reason, we can only conclude that 382 complications tended to decrease when immunosuppressive treatment and the sleeve 383 protection technique were used.

Conclusion

386 Relapse is a major concern after surgical repair of arterial BD. However, the risk seems to be 387 reduced when medical treatment is used in combination with a vascular procedure. This study 388 suggests the need for targeted perioperative medical management to reduce the risk of arterial 389 recurrence in BD patients. To this end, a multidisciplinary approach combining 390 rheumatologists and vascular surgeons is mandatory. 
391 The use of sleeve anastomosis may reduce the risk of recurrence in the form of anastomotic

392 pseudoaneurysms. However, further studies are needed to confirm its efficacy.

393

394

395 
397 1. Sakane T, Takeno M, Suzuki N, Inaba G. Behcet's disease. N Engl J Med.

398 1999;341(17):1284-91.

399 2. Yazici H, Yurdakul S, Hamuryudan V. Behcet disease. Curr Opin Rheumatol.

$400 \quad 2001 ; 13(1): 18-22$.

401 3. Mizuki N, Meguro A, Tohnai I, Gul A, Ohno S, Mizuki N. Association of Major

402 Histocompatibility Complex Class I Chain-Related Gene A and HLA-B Alleles with Behcet's

403 Disease in Turkey. Jpn J Ophthalmol. 2007;51(6):431-6.

404 4. Takeuchi M, Kastner DL, Remmers EF. The immunogenetics of Behcet's disease: A 405 comprehensive review. J Autoimmun. 2015;64:137-48.

406 5. Calamia KT, Schirmer M, Melikoglu M. Major vessel involvement in Behcet disease.

407 Curr Opin Rheumatol. 2005;17(1):1-8.

408 6. Hamza M. Large artery involvement in Behcet's disease. J Rheumatol.

409 1987;14(3):554-9.

410 7. Houman MH, Neffati H, Braham A, Harzallah O, Khanfir M, Miled M, et al. Behcet's

411 disease in Tunisia. Demographic, clinical and genetic aspects in 260 patients. Clin Exp

412 Rheumatol. 2007;25(4 Suppl 45):S58-64.

413 8. Saadoun D, Wechsler B, Desseaux K, Le Thi Huong D, Amoura Z, Resche-Rigon M, et

414 al. Mortality in Behcet's disease. Arthritis Rheum. 2010;62(9):2806-12.

415 9. Saadoun D, Asli B, Wechsler B, Houman H, Geri G, Desseaux K, et al. Long-term

416 outcome of arterial lesions in Behcet disease: a series of 101 patients. Medicine (Baltimore).

$417 \quad 2012 ; 91(1): 18-24$.

418 10. Tohme A, Aoun N, El-Rassi B, Ghayad E. Vascular manifestations of Behcet's disease.

419 Eighteen cases among 140 patients. Joint Bone Spine. 2003;70(5):384-9.

420 11. Ates A, Aydintug OT, Duzgun N, Yaman O, Sancak T, Omur ND. Behcet's disease

421 presenting as deep venous thrombosis and priapism. Clin Exp Rheumatol. 2004;22(1):107-9.

422 12. Akdag Kose A, Kayabali M, Sarica R, Kaymaz R, Azizlerli G. The clinical outcome and

423 treatment in Behcet's disease with deep vein thrombosis. Adv Exp Med Biol. 2003;528:495-

424501.

425 13. Bayraktar Y, Balkanci F, Kansu E, Dundar S, Uzunalimoglu B, Kayhan B, et al.

426 Cavernous transformation of the portal vein: a common manifestation of Behcet's disease.

427 Am J Gastroenterol. 1995;90(9):1476-9.

428 14. Saadoun D, Wechsler B, Resche-Rigon M, Trad S, Le Thi Huong D, Sbai A, et al.

429 Cerebral venous thrombosis in Behcet's disease. Arthritis Rheum. 2009;61(4):518-26.

430 15. Bismuth $E$, Hadengue A, Hammel P, Benhamou JP. Hepatic vein thrombosis in

431 Behcet's disease. Hepatology. 1990;11(6):969-74.

432 16. Yuan SM. Cardiothoracic interventions in Behcet's disease. Clin Exp Rheumatol.

433 2014;32(4 Suppl 84):S130-9.

434 17. International Team for the Revision of the International Criteria for Behcet's $D$. The

435 International Criteria for Behcet's Disease (ICBD): a collaborative study of 27 countries on

436 the sensitivity and specificity of the new criteria. J Eur Acad Dermatol Venereol.

437 2014;28(3):338-47.

438 18. Yin H, Li S, Wang M, Hu Z, Wang J, Yao C, et al. The value of endografts in the surgical

439 management of arterial lesions secondary to Behcet disease. J Vasc Surg. 2017;65(2):471-7. 
19. Shen C, Li W, Zhang Y, Li Q, Jiao Y, Zhang T, et al. Outcomes of surgery for patients with Behcet's disease causing aortic pseudoaneurysm: a shift from open surgery to endovascular repair. Clinics (Sao Paulo). 2016;71(6):302-10.

20. Liu Q, Ye W, Liu C, Li Y, Zeng R, Ni L. Outcomes of vascular intervention and use of perioperative medications for nonpulmonary aneurysms in Behcet disease. Surgery. 2016;159(5):1422-9.

21. Kim SW, Lee DY, Kim MD, Won JY, Park SI, Yoon YN, et al. Outcomes of endovascular treatment for aortic pseudoaneurysm in Behcet's disease. J Vasc Surg. 2014;59(3):608-14. 22. Koksoy C, Gyedu A, Alacayir I, Bengisun U, Uncu H, Anadol E. Surgical treatment of peripheral aneurysms in patients with Behcet's disease. Eur J Vasc Endovasc Surg. 2011;42(4):525-30.

23. Kim WH, Choi D, Kim JS, Ko YG, Jang Y, Shim WH. Effectiveness and safety of endovascular aneurysm treatment in patients with vasculo-Behcet disease. J Endovasc Ther. 2009;16(5):631-6.

24. Ozeren M, Mavioglu I, Dogan OV, Yucel E. Reoperation results of arterial involvement in Behcet's disease. Eur J Vasc Endovasc Surg. 2000;20(6):512-9.

25. Alpagut $U$, Ugurlucan $M$, Dayioglu E. Major arterial involvement and review of Behcet's disease. Ann Vasc Surg. 2007;21(2):232-9.

26. Kalko Y, Basaran M, Aydin U, Kafa U, Basaranoglu G, Yasar T. The surgical treatment of arterial aneurysms in Behcet disease: a report of 16 patients. J Vasc Surg. 2005;42(4):6737.

27. Le Thi Huong D, Wechsler B, Papo T, Piette JC, Bletry O, Vitoux JM, et al. Arterial lesions in Behcet's disease. A study in 25 patients. J Rheumatol. 1995;22(11):2103-13.

28. Tuzun H, Besirli K, Sayin A, Vural FS, Hamuryudan V, Hizli N, et al. Management of aneurysms in Behcet's syndrome: an analysis of 24 patients. Surgery. 1997;121(2):150-6. 29. Yang SS, Park KM, Park YJ, Kim YW, Do YS, Park HS, et al. Peripheral arterial involvement in Behcet's disease: an analysis of the results from a Korean referral center. Rheumatol Int. 2013;33(8):2101-8.

30. Tuzun H, Seyahi E, Arslan C, Hamuryudan V, Besirli K, Yazici H. Management and prognosis of nonpulmonary large arterial disease in patients with Behcet disease. J Vasc Surg. 2012;55(1):157-63.

31. Park MC, Hong BK, Kwon HM, Hong YS. Surgical outcomes and risk factors for postoperative complications in patients with Behcet's disease. Clin Rheumatol. 2007;26(9):1475-80.

32. Hosaka A, Miyata T, Shigematsu H, Shigematsu K, Okamoto H, Ishii S, et al. Long-term outcome after surgical treatment of arterial lesions in Behcet disease. J Vasc Surg. 2005;42(1):116-21.

33. Ding ZY, Jin GN, Ai X, Li LY, Zheng P, Guan Y, et al. Endovascular Treatment of Behcet Disease With Recurrent Infrainguinal Arterial Pseudoaneurysms: A Case Report and Literature Review. Medicine (Baltimore). 2016;95(19):e3545.

34. Kwon Koo B, Shim WH, Yoon YS, Kwon Lee B, Choi D, Jang Y, et al. Endovascular therapy combined with immunosuppressive treatment for pseudoaneurysms in patients with Behcet's disease. J Endovasc Ther. 2003;10(1):75-80.

35. Yamamoto $Y$, Inoue $Y$, Ichinose T, Nishizawa M, Igari K, Toyofuku T, et al. Multiple Recurrent Pseudoaneurysms after Endovascular Repair of Abdominal Aortic Aneurysm in a Patient with Behcet's Disease. Ann Thorac Cardiovasc Surg. 2018;24(6):315-9. 
36. Hatemi G, Christensen R, Bang D, Bodaghi B, Celik AF, Fortune F, et al. 2018 update of the EULAR recommendations for the management of Behcet's syndrome. Ann Rheum Dis.

488 2018;77(6):808-18.

489 37. Balcioglu O, Ertugay S, Bozkaya H, Parildar M, Posacioglu H. Endovascular Repair and 490 Adjunctive Immunosuppressive Therapy of Aortic Involvement in Behcet's Disease. Eur J 491 Vasc Endovasc Surg. 2015;50(5):593-8.

492 38. Park JH, Chung JW, Joh JH, Song SY, Shin SJ, Chung KS, et al. Aortic and arterial 493 aneurysms in behcet disease: management with stent-grafts--initial experience. Radiology. 494 2001;220(3):745-50.

495 39. Kwon TW, Park SJ, Kim HK, Yoon HK, Kim GE, Yu B. Surgical treatment result of 496 abdominal aortic aneurysm in Behcet's disease. Eur J Vasc Endovasc Surg. 2008;35(2):17349780.

498 40. Liu CW, Ye W, Liu B, Zeng R, Wu W, Dake MD. Endovascular treatment of aortic 499 pseudoaneurysm in Behcet disease. J Vasc Surg. 2009;50(5):1025-30.

500 41. Nakai M SS, Kato G, Mitsui H, Sano S. Successful open surgery for recurrent pseudo501 aneurysm after endovascular aneurysm repair in a patient with Behçet's disease. EJVES 502 Extra. 2010;20(1):e8-e10.

503 42. Ferretto L, Piazza M, Bonvini S, Battocchio P, Grego F, Ricotta JJ. ViPS (Viabahn 504 Padova Sutureless) technique: preliminary results in the treatment of peripheral arterial 505 disease. Ann Vasc Surg. 2012;26(1):34-9.

506 43. Ozguler Y, Leccese P, Christensen R, Esatoglu SN, Bang D, Bodaghi B, et al. 507 Management of major organ involvement of Behcet's syndrome: a systematic review for 508 update of the EULAR recommendations. Rheumatology (Oxford). 2018;57(12):2200-12. 509 44. Freyrie A, Paragona O, Cenacchi G, Pasquinelli G, Guiducci G, Faggioli GL. True and 510 false aneurysms in Behcet's disease: case report with ultrastructural observations. J Vasc 511 Surg. 1993;17(4):762-7. 